\title{
Assessment of Cooling Methods for Increased Power Density in Electrical Machines
}

\author{
C. Tighe, C. Gerada, S. Pickering
}

\begin{abstract}
A comprehensive thermal analysis of three different electrical machines is presented, with a view of identifying design aspects that can be exploited to achieve higher power density. A review of some novel cooling methods is initially made. Following this, the stator and rotor thermal resistance paths of the three selected machines are created and the individual components of each resistance path mathematically analysed to identify the parts of the machines that provide greatest potential to reduce stator and rotor temperatures. This is verified with a Design of Experiments analysis on the thermal resistance models of each. Finally, a different novel cooling method is applied to the model of each machine, demonstrating the typical temperature reductions that can be achieved.
\end{abstract}

Index Terms-Thermal management, electrical machines, lumped parameters, permanent magnet, induction,

\section{INTRODUCTION}

The achievable power density of electrical machines is increasing over time due to novel electromagnetic topologies, improved material properties, improved thermal management techniques, improved manufacturing methods and greater design and analysis tools. Of all the barriers to increasing power density, keeping components within their operational temperature is a major constraint. Losses within an electrical motor are tightly linked to the output power. Increasing power density naturally leads to increasing loss density and reduced cooling surface areas. Better cooling of electrical machines is therefore vital to achieve higher power densities.

Thermal resistance networks are an effective way of simulating the thermal performance of electrical machines. They are widely used and proven in electrical machine design, popular due to their simplicity, speed and flexibility in accommodating variations in design and new design features. This technique is used for the modelling work presented, the machine geometries represented in a parameterised thermal resistance network created in Microsoft Excel. It features a fluid network to predict the distribution of coolant flow and the local heat transfer coefficients, coupled to a thermal network which uses information form the flow network to calculate machine temperatures based on the geometry, materials, and losses.

Acknowledgemant goes to EPSRC for their support in this work.

C.Tighe is with the Division of Electrical Systems and Optics, University of Nottingham, United Kingdom (e-mail: christopher.tighe@nottingham.ac.uk)

C. Gerada is with the Division of Electrical Systems and Optics, University of Nottingham, United Kingdom

S. Pickering is with the Division of Energy and Sustainability, University of Nottingham, United Kingdom

\section{Review of Selected Cooling Methods}

A wide range of approaches have been undertaken in order to achieve lower temperatures in electrical machines. Some of these approaches are progressive increments, improving the effectiveness of established cooling methods. Many others are more novel approaches to cooling, often resulting in modifications to the traditional electrical machine structure. ThereF are many enhanced cooling techniques published. This paper does propose itself as a comprehensive literature review, and and examines only a selected few.

Water cooling of the stator is common practice in many applications, where a cooling jacket is located within the stator housing. Efforts to channel the coolant closer to the stator windings have been made, such as those presented in [1]. Different stator arrangements for a Permanent Magnet Synchronous Motor (PMSM) are considered whereby the coolant path passes in between stator windings, acting as a flux barrier. Both radial flow and axial flow is considered, as well as a more extreme cooling setup which passes the coolant through the stator and into the airgap. A decrease in slot temperature of up to $10 \%$ was reported for the stator cooled arrangements. When the cooling path extends to flooding the airgap, magnet temperatures were reduced by $50 \%$ under peak conditions. Although pressure drops were not evaluated, comments were made highlighting the increase in pumping power required to deliver coolant through these complex coolant path arrangements.

A range of cooling options for a high speed PMSM is presented in [2]. The more common indirect oil jacket cooling was considered alongside different direct cooling options: wet stator cooling, wet rotor cooling and spray cooling onto stator overhangs. A Computational Fluid Dynamics (CFD) analysis of the wet stator cooling arrangement is made, which passes oil axially through the stator (sealed from the rotor region) through channels beneath the stator wedge and on the outer diameter of the stator lamination. Temperatures are compared to those when the water jacket method is applied, with a $20 \%$ stator and $8 \%$ rotor temperature reduction reported.

Another direct cooling technique is described in [3], which proposes laminated stator windings through which air is passed. This provides forced cooling directly onto the stator windings. A conjugate CFD model simulating the arrangement, with a flow rate of $300 \mathrm{l} / \mathrm{min}$ of air passing through the windings yielded a maximum temperature of $138^{\circ} \mathrm{C}$ with a heat input of $480 \mathrm{~W}$. Extrapolating this data, a current density of $30 \mathrm{~A} / \mathrm{mm}^{2}$ is achievable within temperature limits.

Improvements to cooling can be achieved by methods other 


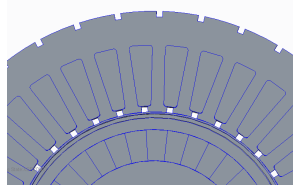

Fig. 1. Sliced side view (right) and axial view (right) showing the coolant flow paths in the direct-cooled PMSM.

than concentrating the cooling medium closer to the heat source, as demonstrated in [4] and [5] where a high thermal conductivity heat flow path is inserted into the slot to reduce the winding hot spot temperature. A lumped-parameter thermal model is presented and used along with finite-element analysis to investigate the effectiveness of the proposed technique. A reduction in stator winding hot spot of $40 \%$ is demonstrated, a figure which is validated experimentally on a purposely built instrumented setup. The paper also addresses the affect of increased induced losses within the slot due to the introduction of the thermal path, and demonstrates ways of reducing these losses.

The use of heat pipes in electrical machines is not a new idea, and has received some attention over the years. Different options for their use are considered in [6], one interesting application being embedded in the shaft to transfer heat from the rotor straight to the outside of the machine.

\section{MACHINES AT STUDY}

The three electrical machines identified for the study cover different machine structures, operating speeds and cooling mechanisms.

\section{A. Permanent Magnet Synchronous Machine, Direct Cooling}

Motor A is a Permanent Magnet Synchronous Machine (PMSM), identical to that analysed in [2]. Fig. 1 shows the stator of the motor, which is cooled by oil pumped into one end of the stator region, flows along axial passages at the inner and outer diameter of the stator, and out through the opposite end of the machine. A sleeve isolates the oil from the rotor region, which is cooled by the circulating enclosed air, which in turn dissipates heat to the oil via the sleeve.

\section{B. Permanent Magnet Synchronous Machine, Indirect Cooling}

Motor B is a PMSM designed as a traction machine with a water jacket running circumferentially around the outside of the stator. The width of the cooling jacket encompasses the entire core length. The permanent magnet rotor is cooled via the enclosed air space, which dissipates heat to the coolant via the housing surfaces.

\section{High Speed Induction Machine, Indirect Cooling}

Motor C is a small High Speed Induction Machine (HSIM) operating at relatively high speeds. The spiral water jacket runs around the housing for the entire length of the machine. The copper cage rotor is cooled via the enclosed air space, which dissipates heat to the coolant via the housing surfaces.
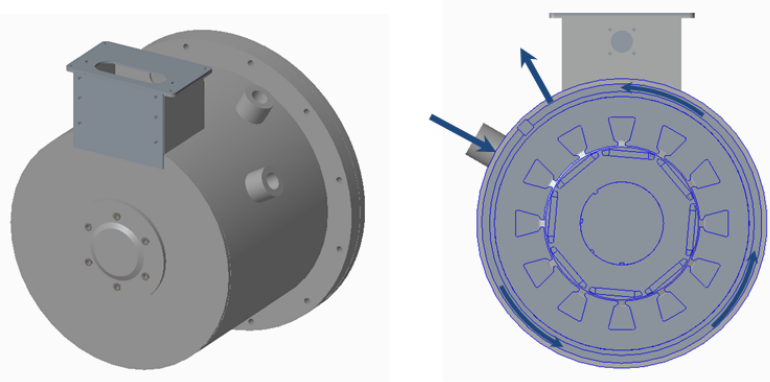

Fig. 2. The indirect-cooled PMSM, with the coolant flow paths indicated on the right.

\section{Thermal Resistance Path AnAlysis}

A thermal resistance model of each machine in the study was created in Excel. The process of developing a thermal resistance network is an established process, and detailed in many publications, such as [7]. Periodicity and symmetry allows half of a single stator slot to be modelled, and half of one rotor pole/slot. Nodes were placed in the radial plane to capture the temperature at different places in the rotor and stator. The radial node arrangement was axially repeated to create three axial sections within the core. Resistances were calculated between adjacent nodes (both axially and radially) based on the geometry and thermal conductivity of the conducting material. Convection resistances were calculated similarly, using a heat transfer coefficient calculated from appropriate correlations [8,9]. At each axial section, nine nodes were places within the portion of the stator slot modelled in a $3 \times 3$ arrangement, allowing the temperature profile within the slot to be well captured. A single node was placed in the tooth, one in the back iron and one in the frame.

Resistances between nodes typically pass through different materials and are therefore made up of separate resistive components, summed for the total series resistance. With resistances calculated, an analytical analysis of the resistance paths was performed to assess which components of the resistance contributed the most in the different machines. The paths considered were from the centre of the stator winding to all available coolant, and from the magnet or rotor bar to the coolant. In the case of the stator winding resistance paths, only radial resistances were analysed as this is the primary cooling path due to the location of the coolant. Rotor resistances considered heat paths to the surrounding air through radial and axial surfaces, and then to the coolant via the stator and through the end of the housing.

\section{A. Stator Winding to Coolant}

1) Thermal Resistance Paths: In the two indirect-cooled machines, Motor A and Motor C, there are two resistance paths out of the winding: through the top of the slot to the yoke and through the slot side walls to the tooth. As there is no coolant flow in the airgap, this is not a primary cooling path. Heat flowing through the side walls to the tooth then conducts radially to the yoke. From the yoke, all heat travels radially through the housing and to the coolant flow. 


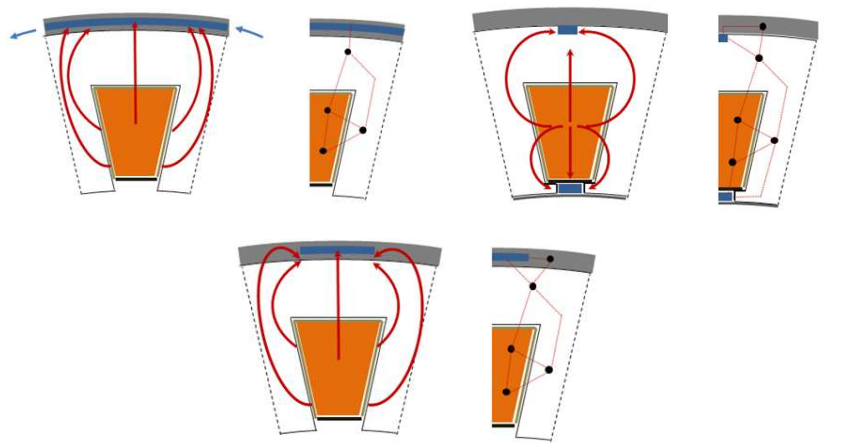

Fig. 3. Overall resistance paths from the stator winding to the coolant. From Top to Bottom: Motor A, Motor B, Motor C.

The stator cooling resistance paths are depicted in Fig. 3. This flow path is also applicable to the direct-cooled Motor $\mathrm{B}$, which has an oil cooling channel between stator core and housing. An additional oil channel in Motor B flows beneath the stator wedge of the stator slot. This provides extra heat paths from the windings: through the slot wedge directly to the inner coolant, and via the tooth (from the slot side walls) to the inner coolant. Fig. 3 shows these cooling paths.

2) Critical Resistances : To reduce the winding temperature, the overall thermal resistance between the winding and coolant should be decreased. In order to understand the best ways to reduce temperature, it must first be understood how each resistance component contributes to the total resistance.

The overall thermal resistance between the winding and the coolant was calculated in each model, considering all paths in series and parallel. Each resistance component is set in turn to zero, and the newly calculated overall resistance compared to the original. The decrease indicates the maximum potential which is achievable by improving heat transfer through that particular component. Table I lists the different components in the resistance path, along with the calculated maximum achievable reduction in the overall resistance. This is calculated for each of the three machines separately.

It can be seen that in each case an improvement in the conduction through the winding provides a high potential to reduce the total resistance, with values ranging from $36 \%$ (Motor B) to $78 \%$ (Motor C). The convection to the coolant is a further component that shows promise for reducing winding temperature. Reductions in overall resistance of up to $76 \%$ can be achieved in Motor B, and 22\% in Motor A. Motor C cannot be cooled much further by improving the coolant convection, due to the already high flow rate and heat transfer coefficient

\section{B. Rotor to Coolant}

1) Thermal Resistance Paths: The resistance paths from the magnet/rotor bar (referred to as rotor active component herein) for the three machines are all relatively similar. From the active component, heat can conduct radially to the outer diameter of the rotor to the airgap. From here it can convect to the inner bore of the stator, and conduct radially through the stator to the coolant. When considering conduction through the stator, the only path analysed is through the tooth to the yoke.
TABLE I

POTENTIAL REDUCTION IN OVERALL RESISTANCE BETWEEN STATOR WINDING AND COOLANT FOR EACH COMPONENT IN THE COOLING PATH.

\begin{tabular}{|c|c|c|c|}
\hline & $\begin{array}{c}\text { Machine } \\
\text { A }\end{array}$ & $\begin{array}{c}\text { Machine } \\
\text { B }\end{array}$ & $\begin{array}{c}\text { Machine } \\
\text { C }\end{array}$ \\
\hline \hline $\begin{array}{c}\text { Conduction } \\
\text { through Slot }\end{array}$ & $36 \%$ & $49 \%$ & $78 \%$ \\
\hline $\begin{array}{c}\text { Slot Wall } \\
\text { Insulation }\end{array}$ & $1 \%$ & $9 \%$ & $6 \%$ \\
\hline $\begin{array}{c}\text { Slot Wedge to } \\
\text { Airgap }\end{array}$ & $<1 \%$ & - & - \\
\hline Stator Tooth & $10 \%$ & $<1 \%$ & $12 \%$ \\
\hline Stator Yoke & $3 \%$ & $20 \%$ & $6 \%$ \\
\hline Frame & $<1 \%$ & $2 \%$ & $<1 \%$ \\
\hline $\begin{array}{c}\text { Convection to } \\
\text { Coolant }\end{array}$ & $76 \%$ & $22 \%$ & $2.5 \%$ \\
\hline \multicolumn{2}{|l}{} \\
\hline
\end{tabular}

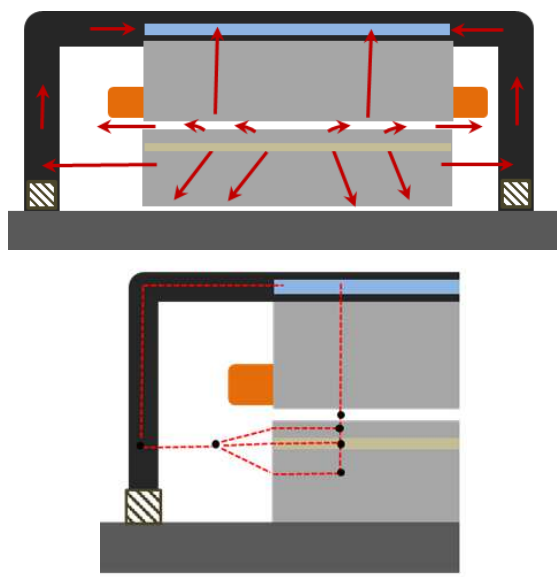

Fig. 4. Thermal paths from the rotor to the coolant for the water jacket machines. The lower image shows the resistance paths used for calculating the overall thermal resistance.

The low thermal conductivity of the stator winding makes it a very poor heat path and the vast majority of heat will be through the parallel path via the tooth. In Motor B there is a cooling channel on the inside of the stator slot. As this coolant is immediately available to the airgap, conduction through the stator to the outer cooling channel is considered negligible and ignored.

An additional cooling path for the rotor active component is to conduct axially to the end faces of the rotor, convecting to the air in the rotor end region. From here, it is able to convect to the housing endcaps and conduct to the outer frame and then to the coolant. Again, this path is ignored for Motor B as it is noted to be only a minor heat due to the availability of the inner cooling channel near the airgap. Fig. 4 shows the thermal paths described from an axial perspective.

2) Critical Resistances: To determine the major resistances between active component in the rotor and coolant, the same method was used as for the stator analysis. In each case the overall resistance between the rotor bar or magnet and the coolant was calculated. Each component of the resistance was then set to zero in turn, and the impact of the overall resistance assessed. Table II shows the maximum reduction possible to the overall resistance by improving the heat transfer through each component. In each case, the airgap convective heat 
TABLE II

POTENTIAL REDUCTION IN OVERALL RESISTANCE BETWEEN ROTOR BAR OR MAGNET AND COOLANT FOR EACH COMPONENT IN THE COOLING PATH.

\begin{tabular}{|c|c|c|c|}
\hline & $\begin{array}{c}\text { Machine } \\
\text { A }\end{array}$ & $\begin{array}{c}\text { Machine } \\
\text { B }\end{array}$ & $\begin{array}{c}\text { Machine } \\
\text { C }\end{array}$ \\
\hline \hline Magnet & $5 \%$ & $2 \%$ & - \\
\hline Rotor Bar & - & - & $<1 \%$ \\
\hline Rotor Lamination & $1 \%$ & $3 \%$ & $<1 \%$ \\
\hline $\begin{array}{c}\text { Air Gap } \\
\text { Convection }\end{array}$ & $88 \%$ & $87 \%$ & $85 \%$ \\
\hline Stator Tooth & $<1 \%$ & $2 \%$ & $6 \%$ \\
\hline Stator Yoke & - & $2 \%$ & $2 \%$ \\
\hline Frame & - & $<1 \%$ & $1 \%$ \\
\hline Coolant & $6 \%$ & $3 \%$ & $3 \%$ \\
\hline & & & \\
\hline $\begin{array}{c}\text { End Region } \\
\text { Convection }\end{array}$ & - & $32 \%$ & $46 \%$ \\
\hline Housing Endcap & - & $4 \%$ & $2 \%$ \\
\hline
\end{tabular}

transfer shows the greatest potential decrease in total resistance to the coolant. This is followed by the convection in the end regions for the indirect-cooled machines. For the direct-cooled machine end region heat transfer was not considered, and the airgap is the only notable resistance with a potential reduction of $87 \%$, the next largest potential reduction being $6 \%$.

\section{Sensitivity Analysis on Selected Parameters}

The thermal resistance analysis identifies components of the cooling resistance paths that should be targeted for reducing machine temperatures. Four components were identified as being particularly key for potentially reducing stator and rotor temperatures: convection to the coolant, conduction through the stator winding, convection to the airgap and convection to the rotor end regions. These were translated to real-life parameters of the machine that can be improved: Heat Transfer Coefficient (HTC) to the coolant, effective radial thermal conductivity of the windings, HTC to the airgap and HTC to the end region.

A Design of Experiments was performed in the thermal model of each machine to better quantify the impact of reducing each of these four resistances. A full factorial Design of Experiments (DOE) was run, the four factors being the machine parameters listed above. Each resistance was tested at two levels, the original resistance value, calculated based on the machine design, and a value twice as large as the original value, thus producing a reduced thermal resistance. The response of the stator winding hot-spot and magnet hot spot (or rotor-bar hot spot in Motor C) was analysed. The thermal resistance network model was run in each case, assuming the same losses.

\section{A. Results}

Fig. 5 and Fig. 6 show the Main Effects plots for the DOE, examining the response in the Stator Hot Spot and Rotor Magnet/Bar temperature, respectively. The average temperature is calculated across all of the runs when the level of each factor is at a certain value. This allows the change in the temperature response to be seen based on the average value of the temperatures calculated at the two values looked at. The greater the gradient in the plot, the greater the impact of changing that parameter on the temperature.

1) Stator Winding Hot Spot: The DOE results in Fig. 5 correlate with the expected results determined by the resistance path analysis. Each model demonstrated that the stator winding radial thermal conductivity has a significant effect on the stator winding temperature, demonstrated by a high gradient in the Main Effects plots. For Motor A and Motor C this by far the greatest influencing factor, and for Motor B it was second only to the coolant HTC. The influence of the coolant HTC on the stator winding temperature is more inconsistent. Whereas it has a large influence in Motor B and to slightly lesser extent Motor A, it affects the stator winding temperature only a small amount for Motor C.

This is in line with the predictions from the resistance path analysis, and therefore can be attributed to the design of the machines. Those with large coolant areas and high heat transfer coefficients operate with low thermal resistances to the coolant, and therefore further improvements have less impact. Both airgap HTC and Rotor End Region HTC have limited influence on the stator winding temperature, as expected.

2) Rotor Temperature : The rotor results in Fig. 6 show the airgap HTC is shown to be the greatest single influence on the rotor temperature in all machines examined. Rotor temperatures in Motor $\mathrm{A}$ and Motor $\mathrm{C}$ are influenced primarily by the airgap HTC, with a moderate influence from the Rotor End Region HTC. Motor B temperatures are not affected much by the Rotor End Region HTC. This is not surprising; this factor was omitted from the initial resistance path analysis due to its predicted lack of importance.

The coolant HTC has a small effect on the rotor temperatures. In the direct-cooled machine, this is due to the close proximity of the coolant to the airgap. In the indirect-cooled machines, it is likely a reduction in the stator temperature leads to a reduced rotor temperature by dissipating less heat into the airgap which is key to the rotor cooling. This is backed up by the fact the stator winding conductivity has a similar impact on the rotor temperature.

\section{Application of Advanced Cooling Techniques}

The above analysis of each of the machines has demonstrated the most effective ways of reducing the temperatures. Putting this analysis into use, a different advanced cooling technique was simulated for each machine. The cooling method applied and the thermal modelling results are presented below.

\section{A. Cooling methods Applied}

1) Motor A: Slot Heat Path: Motor A show stator critical temperatures, the permanent magnets generally having low losses. To reduce stator temperature most effectively, it has been proven that increasing the stator slot thermal conductivity holds the most potential. A similar approach taken in [4], as discussed in the Review of Cooling Methods section, was adopted placing a ' $\mathrm{T}$ ' shaped copper insert to the slot, as shown in Fig. 7. This provides an uninterrupted high-conductivity 

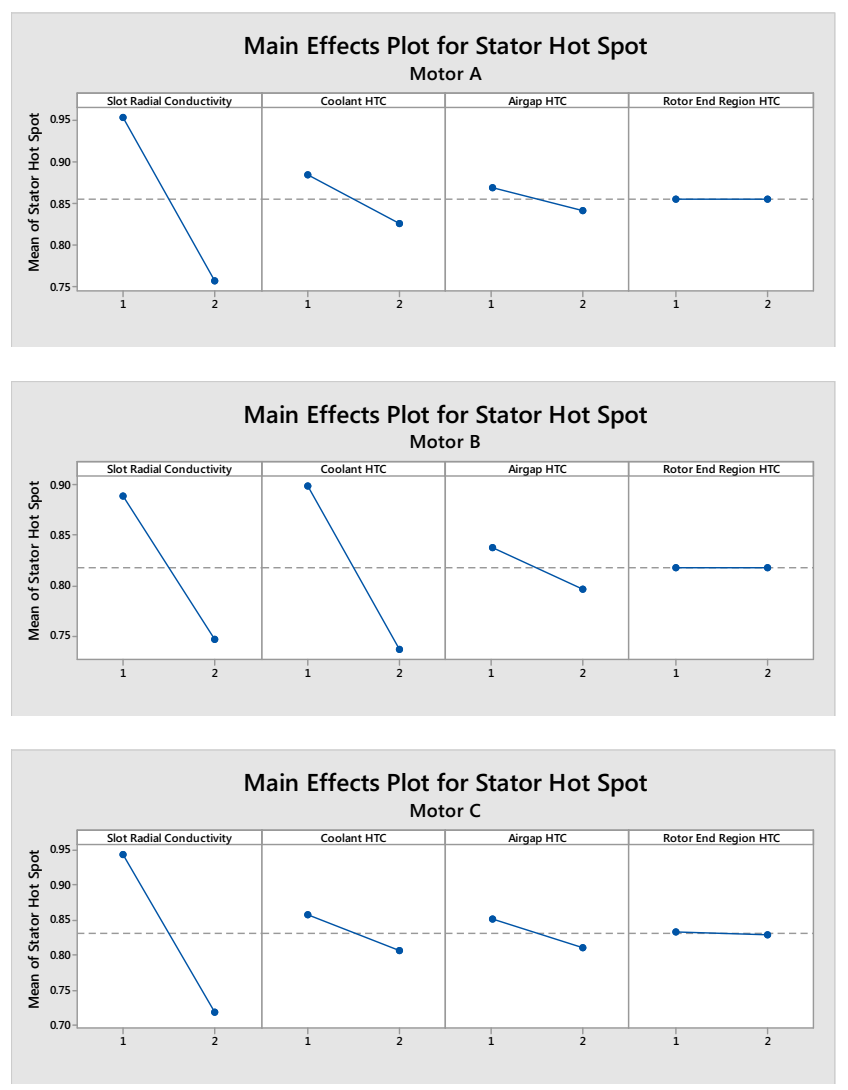

Fig. 5. Main Effect Plots for the normalised maximum Stator temperature from the DOE, showing the average maximum Stator temperature at each variable value.

thermal path from the centre of the slot to the bottom of the slot, where the long base of the copper insert provides a large contact area to the stator lamination.

A range of copper insert thicknesses were simulated, providing a thermal path at the different places in the copper. Surrounding the insert, the slot was simulated with an effective thermal conductivity as before, calculated based on the slot fill factor. A range of copper insert thicknesses were modelled to investigate the optimal thickness. With the presence of the copper insert, the space available for the conductors reduces which can either lead to an increase in the slot fill factor if the winding arrangement is maintained, or the number of conductors (or conductor size) can be reduced to keep the slot fill factor the same. Both scenarios were investigated, presented in Fig. 8.

The results demonstrate that the presence of the copper insert can reduce the maximum slot temperature by up to $50 \%$. A $0.2 \mathrm{~mm}$ copper insert, the thinnest modelled, reduces the temperature by over $20 \%$. As the copper insert thickness increases, the benefits depend on how the slot fill is treated. When a constant slot fill is maintained the benefits appear to change very little, fixing the hot spot reduction at around $20 \%$. If the original winding is compressed into the available area left by the insert, the temperature reduces further with slot insert thickness. The decrease in temperature with insert thickness is driven by the increase in effective thermal conductivity due to the higher slot fill factor.
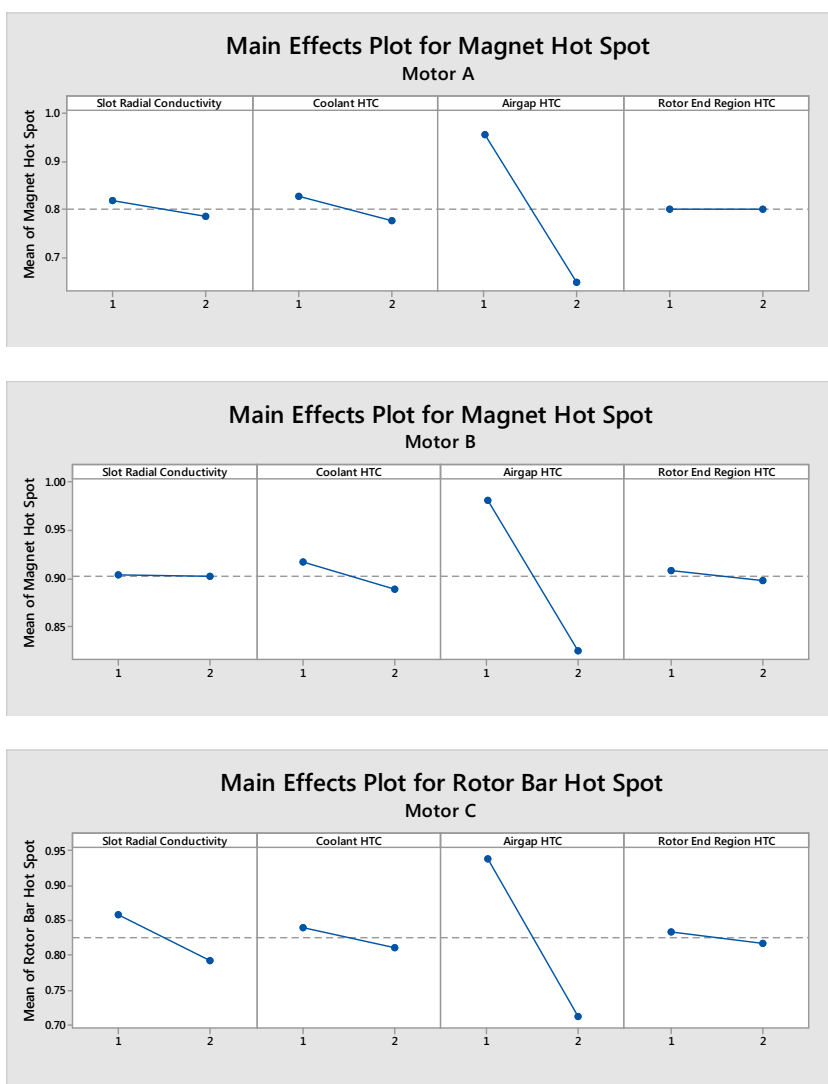

Fig. 6. Main Effect Plots for the normalised maximum Rotor temperature from the DOE, showing the average maximum Rotor temperature at each variable value.

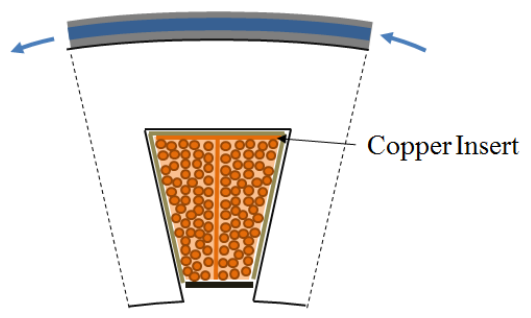

Fig. 7. Use of a Copper Insert in the stator slot of Motor A to improve thermal conductivity.

Further reductions could be achieved by optimisation of the copper insert shape. Extra losses incurred in the copper insert have also been ignored. A non-magnetic material with high thermal conductivity such as aluminium may be a more practical option. Effects on losses and the electromagnetic design by the presence of a thermal path such as this were considered in [4], where it was shown to be a viable design option.

2) Motor B: Laminated Windings: Like Motor A, reducing the stator temperature is the criteria for Motor B. Copper inserts could be similarly effective, however as the stator is already flooded and directly cooled, a different approach was taken to exploit this. The axial oil passages running along the core were removed, and instead a laminated winding was simulated, similar to that described by [10], and described 


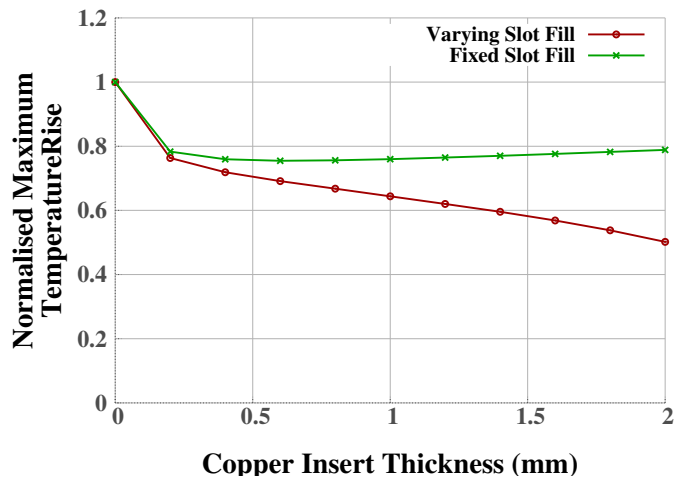

Fig. 8. Impact of the stator slot copper insert on the stator hot-spot temperature.

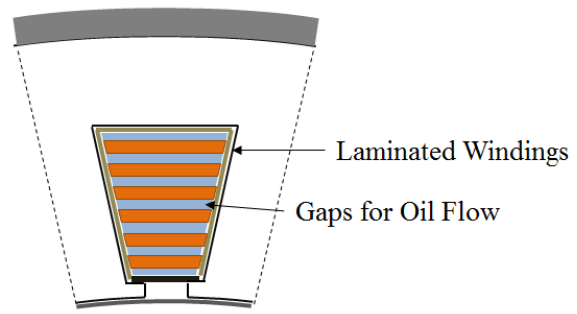

Fig. 9. Laminated stator windings.

earlier. The laminated winding consisted of flat copper conducted, layered radially within the slot. Gaps between each lamination provided a flow passage for the oil, replacing the axial passages previously located by the stator teeth and at the outer stator bore. These passages in between the laminated windings allows the winding to be directly cooled by the oil. As the winding laminations are solid copper (enameled for insulation), the thermal resistance to coolant is significantly reduced.

Three different lamination arrangements were considered, where the winding copper was split into 4, 6 and 8 laminations. These were compared to the stator temperature in the original Motor B design, and are presented in Fig. 10. The losses and the total flow rate of oil through the motor are kept constant.

The use of laminations in the winding is shown to greatly reduce the stator temperature, reducing hot spot temperature by between $60 \%$ (4 laminations) and $78 \%$ (8 laminations). Although increasing the number of laminations does reduce the temperature due to the decreased conduction path to a coolant path, the pumping requirements and manufacturing difficulties also increase. The pressure drop is not measured in the analysis, and would require a CFD analysis to assess properly. Additionally it is worth noting that if operation is required at high frequencies significant $\mathrm{AC}$ losses will be incurred. This method is mostly advantageous for at low frequency operation.

3) Motor C: Rotor Shaft Heat Pipe: The induction machine shows higher temperatures in the rotor, due to the higher rotor losses associated with this type of machine. A reduction in rotor temperature was targeted. The thermal path analysis

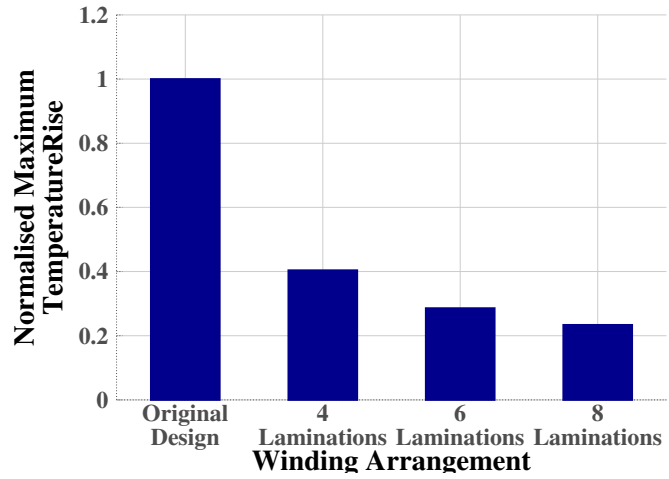

Fig. 10. Comparison of the stator winding hot spot temperature for different winding arrangements in Motor B.

indicated that the best way of reducing rotor temperature is to improve the cooling to the airgap. In practice this is difficult to achieve. Any modifications to the airgap would affect the electromagnetic performance, and increasing the surface area would likely increase windage losses.

Instead, a new thermal path was created for the heat generated in the rotor, by placing a heat sink inside the rotor shaft. The heat sink was simulated to extend inside to cover the entire length of the motor. In this region, the working fluid absorbs the heat from the rotor core, evaporating in the process. The heat sink then extended outside of the machine, into the ambient region. A finned shaft outside the machine housing provides the cooled surface, where heat is extracted from the working fluid (condensing it back to liquid), dissipating the heat straight to ambient. Fig. 11 shows this arrangement.

The design of the heat pipe largely determines the effectiveness. A DOE was carried out, considering 4 parameters that were either unknown, or changeable as part of the design process. These parameters were: the internal HTC of the heat pipe $\left(2000 \mathrm{~W} / \mathrm{m}^{2} \mathrm{~K}\right.$ and $\left.4000 \mathrm{~W} / \mathrm{m}^{2} \mathrm{~K}\right)$, the contact thickness between the heat pipe and shaft (zero contact thickness and $100 \mu \mathrm{m})$, the number of fins on the external shaft at the condenser side (5 and 10) and the overhang length of the heat pipe over which condensation occurs $(135 \mathrm{~mm}$ and $67.5 \mathrm{~mm})$.

The results in 12 shows that each one of the parameters considered has a significant effect on the performance of the heat pipe. The worst case scenario modelled yielded a $20 \%$ decrease in the maximum rotor bar temperature, the best case producing a $45 \%$ reduction. The complex behaviour of a heat pipe requires a more detailed analysis to assess the exact benefits, however this preliminary simulation suggests that there are worthwhile reductions in the rotor bar temperature. As a passive device, it could be used effectively, particularly in higher speed applications that produce higher heat transfer coefficients on the external fins. The manufacturing and placement of the heat pipe does present problems, and careful consideration of the effects of machine dynamics must be made, especially at higher speeds.

\section{CONCLUSION}

Power density in electrical machines can be increased through improved cooling, in order to allow greater losses to 


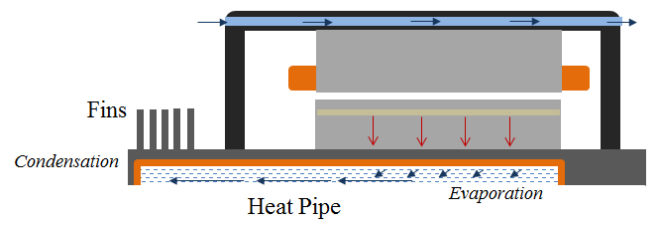

Fig. 11. The working of a heat pipe in the shaft of Motor C.

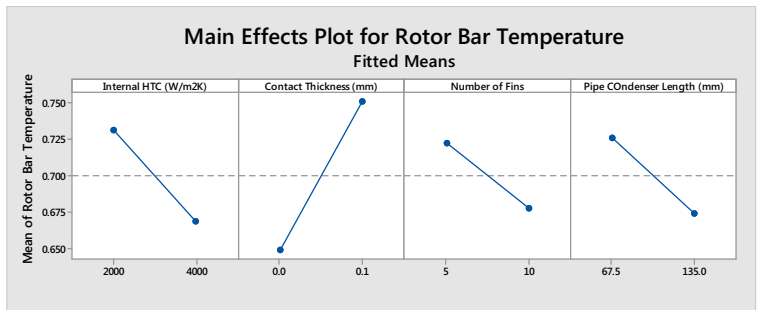

Fig. 12. Main Effect Plots for the Rotor Bar Temperature with different Heat Pipe parameters.

be dissipated in the same area at the same temperature rise. An analytical analysis of thermal resistance paths on three different machine highlight four key resistance components, which were then examined in more detail using a DOE on a thermal resistance network model of each machine.

The key parameter identified in all models for reducing stator winding temperature is the winding radial thermal conductivity. It is typically below or around $1 \mathrm{~W} / \mathrm{mK}$ due to poor slot fill factors and low thermal conductivity of the impregnation resin. Thermal resistance to the coolant is a further parameter that has a notable effect on two of the three machines studied. This resistance can be reduced by increasing the HTC between coolant walls and coolant, or by increasing the surface area. Rotor temperatures can be significantly reduced through improving the airgap and, to a lesser extent, the end region convection resistances.

With knowledge of the aspects of the machines to target, novel cooling methods were simulated in the thermal resistance models to assess their impacts. Stator temperatures were reduced through use of a copper thermal path inside the stator winding, and in another case using laminated stator winding allowing coolant to flow inside. Rotor temperatures can be reduced by use of a heat pipe, although the performance and design of the heat pipe requires a more detailed analysis.

\section{REFERENCES}

[1] A. Nollau and D. Gerling, "Novel cooling methods using flux-barriers," in Electrical Machines (ICEM), 2014 International Conference on, pp. 1328-1333, Sept 2014.

[2] A. La Rocca, S. Pickering, C. Eastwick, and C. Gerada, "Enhanced cooling for an electric starter-generator for aerospace application," in Power Electronics, Machines and Drives (PEMD 2014), 7th IET International Conference on, pp. 1-7, April 2014.

[3] A. Reinap, F. Marquez-Fernandez, R. Andersson, C. Hošgmark, M. Alakušla, and A. Gošransson, "Heat transfer analysis of a traction machine with directly cooled laminated windings," in Electric Drives Production Conference (EDPC), 2014 4th International, pp. 17, Sept 2014.

[4] M. Galea, C. Gerada, T. Raminosoa, and P. Wheeler, "A thermal improvement technique for the phase windings of electrical machines," Industry Applications, IEEE Transactions on, vol. 48, pp. 79-87, Jan 2012.

[5] Z. Xu, C. Tighe, M. Galea, T. Hamiti, C. Gerada, and S. J. Pickering, "Thermal design of a permanent magnetic motor for direct drive wheel actuator," in Electrical Machines (ICEM), 2014 International Conference on, pp. 2186-2192, Sept 2014.

[6] M. Bradford, "The application of heat pipes to cooling rotating electrical machines," in Electrical Machines and Drives, 1989. Fourth International Conference on, pp. 145-149, Sep 1989.

[7] A. Bejan, Heat transfer. John Wiley \& Sons, Inc., 1993.

[8] D. Howey, P. Childs, and A. Holmes, "Air-gap convection in rotating electrical machines," Industrial Electronics, IEEE Transactions on, vol. 59, pp. 1367-1375, March 2012.

[9] D. Staton and A. Cavagnino, "Convection heat transfer and flow calculations suitable for analytical modelling of electric machines," in IEEE Industrial Electronics, IECON 2006 - 32nd Annual Conference on, pp. 48414846, Nov 2006.

[10] A. Reinap, C. Högmark, K. Frogner, F. Lundström, M. Andersson, M. Alaküla, and L. Wang, "Electrical machine design with directly cooled laminated fractional pitch windings," 2015.

\section{BIOGRAPHIES}

C Tighe received the MEng and Ph.D. degrees in mechanical engineering from the University of Nottingham, U.K., in 2007 and 2011, respectively. Since graduating, he has spent time working in the electrical generator industry. He now works as a Research Fellow at The University of Nottingham, as well as working as a thermal engineering consultant for Electrical Cooling Solutions. His main interests are thermal management of electrical machines and power electronics.

C Gerada obtained his $\mathrm{PhD}$ in Numerical Modelling of Electrical Machines from the University of Nottingham, U.K., in 2005. He subsequently worked as a researcher at Nottingham on high performance electrical machines and drives for high performance applicationsand on the design and modelling of electromagnetic actuators for aerospace applications. He is currently a Lecturer Professor in Electrical Machines within the PEMC research group at Nottingham. He is the Chair of the IEEE IES electrical machines technical committee and an associate editor of the IEEE IAS transactions.

S. J. Pickering received the B.Sc. and Ph.D. degrees in mechanical engineering from the University of Nottingham, Nottingham, U.K., in 1979 and 1984, respectively. Since 1988, he has been a Lecturer with the University of Nottingham, where he is currently a Hives Professor and Reader in the Faculty of Engineering. He has extensive research experience in Thermofluids and has undertaken research into the cooling of electric machines for over ten years. 